\title{
Yoğun bakım ünitesinde takip edilen ergen ilaç intoksikasyonlarının retrospektif değerlendirilmesi
}

\author{
Retrospective evaluation of adolescent drug intoxications followed in the \\ intensive care unit
}

\author{
D Ökkeş Hakan Miniksar¹, (1) Dilşad Yıldız Miniksar² \\ ${ }^{1}$ Anesteziyoloji ve Reanimasyon Anabilim Dalı, Yozgat Bozok Üniversitesi, Tip Fakültesi, Yozgat, Türkiye \\ ${ }^{2}$ Çocuk ve Ergen Ruh Sağlığı ve Hastalıkları Anabilim Dalı, Yozgat Bozok Üniversitesi, Tıp Fakültesi, Yozgat, Türkiye
}

Cite this article as / Bu makaleye atıf için: Miniksar ÖH, Miniksar DH. Yoğun bakım ünitesinde takip edilen ergen ilaç intoksikasyonlarının retrospektif değerlendirilmesi. J Health Sci Med 2020; 3(3); 203-208.

\section{ÖZ}

Amaç: İntoksikasyonlar, çocukluk ve ergenlik dönemi acil hastalıkları arasında morbidite ve mortalitenin önlenebilir nedenleri arasında yer alır. Çalışmamızda akut ilaç intoksikasyonu nedeniyle yoğun bakım ünitesinde takip edilen ergen hastaların demografik ve klinik verilerini retrospektif olarak incelemeyi amaçladık.

Gereç ve Yöntem: Bu retrospektif çalışmada, Malatya Eğitim ve Araştırma Hastanesi Yoğun Bakım Ünitesi (YBÜ)'nde akut ilaç intoksikasyonu tanısıyla tedavi edilen ergen hastaların demografik özellikleri; öncesinde psikiyatrik hastalık varlığı; yoğun bakım ünitesi yatıș süresi; alınan toksik madde; toksik madde alım nedeni; alınan toksik madde ilaç ise cinsi; ilacın formu (tablet, süspansiyon); tek ilaç mı çoklu ilaç mı olduğu; zehirlenmenin gerçekleştiği ay ve komorbiditeleri kaydedilmiştir.

Bulgular: Çalışmamıza 36’sı kız (\%60), 24’ü erkek (\%40) olmak üzere toplam 60 hasta dahil edilmiş olup, hastaların yaş ortalaması $16,6 \pm 1,8$ 'dır. İntoksikasyonların 57 'si (\%95) intihar ile ve 3'ü (\%5) kaza sonucu meydana gelmiştir. İntoksikasyona neden olan ilaçlar sırasıyla antidepresan (\%25), analjezik (\%18,3), antiepileptik (\%5), uyuşturucu madde (\%5), antipsikotik (\%6,6), antigribal (\%5), antibiyotik (\%5) şeklindedir. Hastaların \%65'inde çoklu ilaç alımı, \%35'inde tekli ilaç alımı gözlenmiştir. Hastaların 26 ’sına $(\% 43,6)$ en az bir psikiyatrik

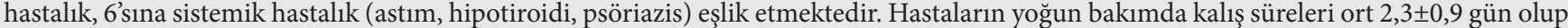
intoksikasyonların en sık kış mevsiminde (\%35) meydana geldiği belirlenmiştir. Bir hasta iki gün mekanik ventilasyon desteği almış, bir hastaya ise hemodiyafiltrasyon uygulanmıştır. Çalışmamızda hiçbir hastada mortalite görülmemiştir.

Sonuç: Çalışmamızda hastaların çoğunun kız olduğu, en sık antidepresan ve analjezik ilaçlar ile intoksikasyonun meydana geldiği ve büyük oranda psikiyatrik hastalık öyküsü varlığı saptanmıştır.

Anahtar Kelimeler: İntoksikasyon, ergen, yoğun bakım

\begin{abstract}
Objective: Intoxications are among preventable causes of morbidity and mortality among childhood and adolescent emergency diseases. In this study, we aimed to retrospectively investigate the demographic and clinical data of adolescent patients followed up in the intensive care unit for acute drug intoxication.

Material and Method: In this retrospective study, demographic characteristics of adolescent patients treated with acute drug intoxication in Malatya Training and Research Hospital Intensive Care Unit (ICU); presence of pre-existing psychiatric illness; length of stay in the intensive care unit; received toxic substance; the reason for ingestion of toxic substances; if the type of toxic substance was a drug; form of the drug (tablets, suspensions); single drug or multiple drug; month of poisoning and their comorbidities were recorded.

Results: A total of 60 patients (36 girls (60\%) and 24 boys (40\%)) were included in the study. The mean age of the patients was 16,6 years. $52(86,6 \%)$ of the intoxications were caused by suicide, $3(5 \%)$ by accident and $5(8,3)$ by drug overdose. Drug intoxication was detected in $91,6 \%$ of the patients. Antidepressant (25\%), analgesic (18,3\%), antiepileptic (5\%), narcotic (5\%), antipsychotic (6,6\%), antigribal (5\%), antibiotic (5\%) uptake were determined. $65 \%$ of patients had multiple drug intake and $35 \%$ had single drug intake. 26 patients (41,6\%) were accompanied by at least one psychiatric disease and 4 patients with systemic disease (asthma, hypothyroidism, psoriasis). The mean duration of ICU stay was 2,3 days, and it was determined that intoxications occurred most frequently in winter (35\%). One patient received mechanical ventilation support for two days and one patient underwent hemodiafiltration. In our study, no mortality was seen in any patient. Conclusion: In our study, it was found that most of the patients were girls, antidepressants and analgesics were the most common drugs in intoxication and history of psychiatric disorders were found significantly.
\end{abstract}

Keywords: Intoxication, adolescent, intensive care 


\section{GíRiş}

İntoksikasyon, vücuda toksik bir maddenin girmesiyle veya toksik olmayan bir maddenin yüksek dozda alınmasıyla vücudun normal fonksiyonlarının bozulmasıdır. İntoksikasyonlar, intihar amaçlı veya farkında olmadan ilaç ya da madde alınması sonucu ortaya çıkabilmektedir (1).

İntihar tüm dünyada çocuk ve ergenlerde önemli toplum sağllğı problemi ve ölüm nedenleri arasında yer almaktadır ve son yıllarda sıklığında belirgin bir artış gözlenmektedir (2). Dünyada ölüm nedenleri arasında onuncu sırada olduğu bildirilmektedir. Her yıl yaklaşık bir milyon insanın intihar sonucu öldügü bilinmektedir (3). Ergenlerde intihar girişimlerinin yaşam boyu prevalansı \%3,5 ile \%11 arasında olup, pek çok gelişmiş ülkede ergenlerin ölüm nedenleri arasında ilk sıralarda yer almaktadır (2). En sık görülen intihar yöntemlerinin başında ise ilaç intoksikasyonları gelmektedir $(2,4)$.

Ergenlik döneminde intihar davranışı için en önemli risk faktörü önceden intihar girişiminde bulunulması olup diğer risk faktörleri eşlik eden psikiyatrik hastalık varlığı (major depresyon, madde kullanımı gibi), ailesel ve çevresel (ailede intihar öyküsü, istismar gibi) etkenlerdir (4). İntihar amaçlı ilaç intoksikasyonlarında risk faktörlerinin ve erken belirleyicilerinin belirlenmesi toplum sağlığı açısından büyük önem taşımaktadır $(4,5)$.

Çalışmamızda ilaç intoksikasyonu tanısıyla erişkin yoğun bakım ünitemize yatırılarak tetkik ve tedavi edilen ergen olgularının demografik özelliklerini, klinik verilerini ve ilişkili faktörleri geriye dönük olarak incelemeyi amaçladık.

\section{GEREÇ VE YÖNTEM}

Malatya Eğitim ve Araştırma Hastanesi Anestezi Yoğun Bakım Ünitesi'nde Ocak 2015-Nisan 2018 tarihleri arasında akut intoksikasyon tanısıyla tedavi görmüş ergen hastaların dosyaları retrospektif olarak incelendi. $\mathrm{Bu}$ çalışma, üniversite/yerel insan araştırmaları etik kurulu tarafından onaylanmış ve insan katılımcıları içeren çalışmalarda gerçekleştirilen tüm prosedürler, kurumsal ve/veya ulusal araştırma komitesinin etik standartlarına, 1964 Helsinki Bildirgesi ve daha sonra yapılan değişikliklere veya karşılaştırılabilir etik standartlara uygun olarak yapılmıştır. Çalışma için Malatya Klinik Araştırmalar Etik Kurulu’ndan 2019/135 tarih/sayı ile etik kurul onayı alınmıştır. Hastaların demografik özellikleri; öncesinde psikiyatrik hastalık varlığı; yoğun bakım ünitesi yatış süresi; alınan toksik madde; toksik madde alım nedeni; alınan toksik madde ilaç ise cinsi, formu (tablet, süspansiyon), tek ilaç mı çoklu ilaç mı olduğu; zehirlenmenin gerçekleştiği ay; ve mortalite oranları kaydedildi. Verilerine sistemden erişilemeyen, çocuk psikiyatri konsültasyonu olmayan ve yatış süresi 24 saat dolmayan hastalar çalışma dişı bırakıldı. İstatistiksel değerlendirmede SPSS (Statistical Program for Social Sciences, 25.0) programı kullanıldı. Veriler tanımlayıcı istatistiksel yöntemler kullanılarak sayı (n), ortalama \pm standart sapma (SS) ve yüzde (\%) olarak verildi.

\section{BULGULAR}

Akut intoksikasyon nedeniyle yoğun bakıma kabul edilen ergen hastalar, yoğun bakım ünitemizde yatan hastaların (4962) \%1,2'sini oluşturmaktadır. Çalışmamıza 36'sı kız (\%60), 24'ü erkek (\%40) olmak üzere toplam 60 hasta dahil edilmiştir. Yaş ortalamasının $16,6 \pm 1,8$ yll olduğu ve yoğun bakımda kalış sürelerinin ortalama $2,3 \pm 0,9$ gün olduğu saptanmıştır. Hastaların demografik özellikleri Tablo 1'de verilmiştir.

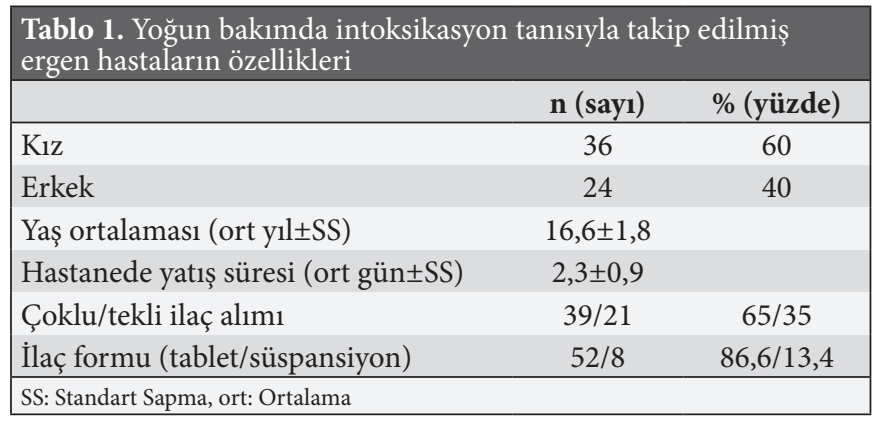

Hastaları incelediğimizde 57'sinin (\%95) intihar amaçl1, 3'ünün (\%5) ise kaza sonucu intoksikasyon yaşadığ 1 görülmüştür. Kaza sonucu meydana gelen olguların hepsinin ilaç dışı madde ile (organofosfat, pestisit) kış mevsiminde meydana geldiği ve eşlik eden psikiyatrik ya da sistemik hastalıklarının olmadığı tespit edilmiştir. İntihar sonucu olan olgularda ise; çoğunun kız $(\% 58,3)$ olduğu, \%45,6’sına psikiyatrik hastalığın eşlik ettiği ve intoksikasyonların en sık kış mevsiminde (\%35) meydana geldiği saptanmıştır (Tablo 2).

Hastaların \%91,6'sı ilaçlar ile intoksikasyona maruz kalmış olup; \%65'ini çoklu ilaç alımı, \%35'ini tekli ilaç alımının oluşturduğu görülmüştür. Alınan ilaçların hepsi oral yolla alınmış olup; \%86,6'sının tablet ve $\% 13,4$ 'ünün süspansiyon formunda olduğu saptanmıştır. İntoksikasyona neden olan ilaçlar Grafik l'de verilmiştir. 


\begin{tabular}{|c|c|c|c|c|}
\hline & \multicolumn{2}{|c|}{ Kaza } & \multicolumn{2}{|c|}{ İntihar } \\
\hline & n (sayı) & \% (yüzde) & n (sayı) & $\%$ (yüzde) \\
\hline \multicolumn{5}{|l|}{ Cinsiyet } \\
\hline $\mathrm{K} 1 \mathrm{z}$ & 3 & 5,4 & 35 & 58,3 \\
\hline Erkek & 0 & 0 & 22 & 36,6 \\
\hline \multicolumn{5}{|l|}{ Etken } \\
\hline İlaç & 0 & 0 & 52 & 86,6 \\
\hline İlaç dışı madde & 3 & 5,0 & 0 & 0 \\
\hline Uyuşturucu madde & 0 & 0 & 5 & 8,3 \\
\hline \multicolumn{5}{|l|}{ Mevsim } \\
\hline Kış & 3 & 5,0 & 18 & 30,0 \\
\hline Yaz & 0 & 0 & 16 & 26,6 \\
\hline İlkbahar & 0 & 0 & 13 & 21,6 \\
\hline Sonbahar & 0 & 0 & 10 & 16,6 \\
\hline Sistemik hastalık & - & - & 6 & 10,5 \\
\hline Psikiyatrik hastalık & - & - & 26 & 45,6 \\
\hline
\end{tabular}

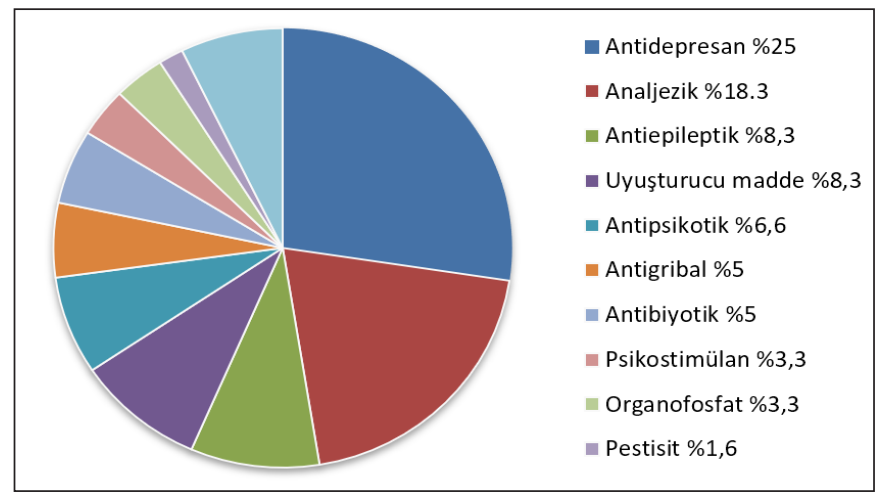

Grafik 1. Yoğun bakımda ergen ilaç intoksikasyonuna neden olan ilaçların dağılımı

Hastaların başvuru şikayetlerinin en sık bulantı-kusma (\%46), karın ağrısı $(\% 26,6)$, baş dönmesi $(\% 13,3)$ olduğu saptanmıştır. Başvuru anında üç hasta konfüze ve bir hastanın ise bilinci kapalı idi. Acil serviste hastaların 42'sine (\%70) aktif kömür verilirken, 32'sine $(\% 53,3)$ gastrik dekontaminasyon uygulanmıştır. Yoğun bakım ünitemizde zehir danışma merkezi önerilerine uyularak acil serviste başlayan semptomatik tedavileri devam etmiştir. Lokal bir antidot olan aktif kömür dışında, aldığ 1 miktar toksik dozun üzerinde olan üç hastaya spesifik antidot tedavisi uygulanmıştır.

Hastaların 26'sına $(\% 43,3)$ psikiyatrik hastalığın ve 6'sına (\%10) sistemik hastalığın eşlik ettiği görülmüştür (Tablo 3).

Çalışmamızda hiçbir hastada mortalite görülmemiştir. Yüksek doz LSD (liserjik asid dietilamid) alan bir hasta yoğun bakımda solunum yetmezliği gelişmesi üzerine iki gün mekanik ventilasyon desteği almış ve kolşisin intoksikasyonu olan bir hastaya ise akut böbrek hasarı gelişmesi üzerine hemodiyafiltrasyon uygulanmıştır.
Tablo 3. Yoğun bakımda ilaç intoksikasyonu ile takip edilen ergen hastalara eşlik eden hastalıklar

n (sayı) \% (yüzde)

\begin{tabular}{|c|c|c|}
\hline \multicolumn{3}{|l|}{ Psikiyatrik hastalıklar } \\
\hline Depresyon & 11 & 18,3 \\
\hline Anksiyete & 5 & 8,3 \\
\hline Uyuşturucu madde bağımlılığı & 5 & 8,3 \\
\hline Borderline kişilik bozukluğu & 3 & 5 \\
\hline Dikkat eksikliği ve hiperaktivite bozukluğu & 1 & 1,6 \\
\hline Psikoz & 1 & 1,6 \\
\hline Toplam & 26 & $\% 43,6$ \\
\hline \multicolumn{3}{|l|}{ Kronik hastalıklar } \\
\hline Epilepsi & 2 & 3.3 \\
\hline Astım & 2 & 3.3 \\
\hline Hipotiroidi & 1 & 1,6 \\
\hline Multiple skleroz & 1 & 1,6 \\
\hline Toplam & 6 & $\% 10$ \\
\hline
\end{tabular}

\section{TARTIŞMA}

Yoğun bakım ünitemizde 3 yıllık süre içinde yatırılarak tedavi edilmiş 60 ergen hastayı retrospektif taradığımız bu çalışmada hastaların çoğunluğunun $\mathrm{kız}$ ergenler (\%60) olduğu görülmüştür. Ülkemizde yapılan çalışmalarda kızların $(\% 84,4) \quad$ erkeklere $(\% 73,8)$ oranla daha fazla intihar girișiminde bulundukları saptanmıştır $(3,5,6)$. Ergenlik döneminde depresyon sıklığının kızlarda erkeklere göre iki kat daha yüksek olması ve kı çocuklarında daha hassas bir dönem haline gelmesi intihar girişiminde riski artırmaktadır $(1,2,5)$. Hastaların yaş ortalamasının $16,6 \pm 1,8$ yıl olduğu hastaların tamamının 15-17 yaş aralığında olduğu tespit edilmiştir. Türkiye'de tüm intihar girişimlerinin \%30-35'i $14-15$ yaş grubu arasında görülmektedir $(7,8)$.

Olgularımızın intoksikasyon nedenlerine göre dağılımı değerlendirildiğinde en çok intihar amaçlı $(\% 86,6)$ zehirlenmeler saptanmıştır. Ergenlik intihar girişimleri için kritik bir dönemdir. Çocuklarda intihar girişiminin nadir olduğu, ergenlikle birlikte sıklığın arttığ bilinmektedir. Ünlü ve ark. (5) yaptıkları çalışmada 12 yaş altında intihar girişiminde bulunan olguya rastlanmamış iken, tüm olguların \%78,7'sini 15-17 yaş aralığındaki ergenlerin oluşturduğu belirlenmiştir. $\mathrm{Bu}$ durum başta duygudurum bozuklukları ve madde kullanım bozuklukları olmak üzere ruhsal bozuklukların ergenlik döneminde artış göstermesiyle açıklanabilir. Ergenliğe geçişle birlikte depresif ve anksiyete belirtileri dahil ruhsal sorunların artıyor olması, bu gelişimsel dönemin doğası ile ilişkili olabilir (9). Ülkemizde yapılan çalışmalar ergenlerin intihar girişimlerinde en sık kullandıkları yöntemin aşırı dozda ilaç alımı olduğunu göstermektedir $(5,10)$. Çalışmamızda tüm intoksikasyon olgularının \%91,6'sı ilaçlar ile, \%5'i ilaç dışı (kaza) maddelerle gerçekleşmiştir. Literatürde çocuklarda 
intoksikasyon üzerine yapılan pek çok çalı̧̧mada, 15-19 yaş grubunda intihar amaçlı zehirlenme olgu sayısı daha fazla iken 2-3 yaş çocuklarda ise kaza ile zehirlenmelerin daha sık olduğu belirtilmiştir (11-13). Özdemir ve ark. (14) yaptıkları bir çalışmada 2251 çocuk intoksikasyon olgularının, \%67,4'ünün kazara, \%25,9'unun intihar amaçlı geliştiğini ve bunların yaklaşık \%64'ünün uyuşturucuya bağlı olduğunu ortaya koymuşlardır. Çalışmamızda, 5 hastada intoksikasyon uyuşturucu madde bağımlılı̆̆ sonucu meydana gelmiştir. Alkol ve madde kullanımı, ergenler için büyük bir tehlike olmakla beraber hayatı tehdit eden bu maddelerin yaygınlaşması sonucu karşılaşılan olgu sayısının artması endişe vermektedir.

Çalışmamızda literatürden farklı olarak intoksikasyonların çoğunluğunun kış (\%35) ve yaz aylarında $(\% 26,6)$ görüldüğü saptanmıştır. Literatürde ergenlerde intihar girişiminin en sık ilkbahar ve yaz aylarında gerçekleştiği bildirilmiştir (12). Bu farklılığın, insanların kış aylarında güneş ışı̆̆ına daha az maruz kalmaları ve sosyalleşmenin azalmasının ruhsal bozuklukları arttırmasından $(8,9,15)$ kaynaklandığını düşünmekteyiz. Mevsimsel değişikliklerin ruhsal durum, enerji düzeyi, uyku süresi, iştah, yemek alışkanlıkları ve sosyal yaşantıyı etkileme derecesi mevsimsellik olarak tanımlanır. İstatistiksel olarak ilkbahar ve sonbahar depresyon için, yaz ise mani için artı̧̧ gösterme zamanıdır (15). Çalıșmamızda yaz aylarında görülen intoksikasyonların muhtemel sebeplerden birisi de ergenin duygu durum değişikliklerini bu aylarda daha fazla yaşamış olması (12) ile açılkanabilir.

Ülkemizde pestisitler tarım alanında sıkça kullanılmaktadır. Tarım ilaçlarının pet şişede buzdolabına koyularak saklanması veya tezgah üzerinde su içerisinde unutulması sonucu kazara intoksikasyonlar meydana gelebilmektedir. Tarım ilaçlarının bilinçsiz ve denetimsiz kullanımının yanı sıra intihar amaçlı içilmesi olgularına da rastlanılmaktadır (13). Çalışmamızda tarım ilacı ile intoksikasyonların tümü (n:3) kazara meydana gelmiş olup, mortalite hiçbir hastada görülmemiştir.

Çalışmamızda antidepresanlar (\%25) intoksikasyona en fazla neden olan ilaç grubu olup, bunu sırasılyla analjezikler $(\% 18,3)$ ve antiepileptikler $(\% 8,3)$ izlemektedir. En sik depresyon $(\% 18,3)$ olmak üzere hastaların \%43,6'sina en az bir psikiyatrik hastalık eşlik etmektedir. Çalışmamızla benzerşsekildedepresifhastalardaintihargirişimiyüksektir $(9,10)$. Çalışmamızda depresyonu olan ergenlerin ilaç tedavilerini yeterince alıp almadıkları bilinmemektedir. Yetersiz dozda ilaç tedavisi mevcut psikiyatrik hastalığın öncelikle iyileşmemesine, kronikleşmesine ve bazen de alkol-madde kullanımıla komplike olmasına yol açarak intihar riskini artırabilir $(10,15,16)$. Finlandiya'da yapılan bir çalı̧̧mada ise intihar girişiminden önce ve sonra aldıkları tedaviler açısından karşılaştırılan major depresyonu olan hastaların girişimden sonra bile sadece \%17'sinin yeterli dozda antidepresan aldıkları gösterilmiştir (16). Bu çalışma da gösteriyor ki psikiyatrik tedavi için kullanılan ilaç dozlarının yeterli olması konusunda özen gösterilmelidir. Çoğu benzer çalışmalarda ilaç intoksikasyonların çoğunluğunu analjezik/antipiretik, antidepresan/antipsikotik ve antibiyotikler oluşturmaktadır $(10,12,17,18)$. Ayrıca Türkiye'de ağrı kesici ve analjezik ilaçlara ulaşımın kolay olması, reçete gerektirmeksizin alınabilmesi, her evde bulunması intihar nedenli intoksikasyonlar ile sık karşılaşmamıza yol açmaktadır (19).

Hastalarımız ergen yaş grubunda olmasından dolayı, tüm hastalar çocuk psikiyatrisi tarafından değerlendirilmiş, intihar amaçlı olanların \%45,6'sında en az bir psikiyatrik hastalık saptanmıştır. Ergenlik dönemindeki intihar girişimlerinde mevcut psikiyatrik bozukluklar da önemli etmen olarak belirtilmektedir (12). Akın ve ark. (2) 1218 yaş ergen intoksikasyonları üzerine yaptıkları bir araştırmada ergenlerin \%77,8'inde en az bir psikiyatrik bozukluk olduğunu saptamışlardır. Bu bozukluklar da sıklı̆̆ına göre sirasılyla depresyon, DEHB (dikkat eksikliği ve hiperaktivite bozukluğu) ve davranım bozukluğu şeklindedir. Çalışmamızda hastaların geçmiş psikiyatrik hastalık tanı varlığına bakıldığında 11'inde depresyon, 5'inde anksiyete bozukluğu, 5'inde madde bağımlılığı, 3'ünde borderline kişilik bozukluğu varlığ saptanmıştır. Bu ruhsal bozukluklar arasında en özgül ilişki duygu durum bozuklukları ile olandır. İntihar eden ergenlerin \%50-75'inde bir duygu durum bozukluğu olduğu bildirilmiştir. Duygu durum bozukluğu (major depresif bozukluk ve/veya distimi) tanısı olan ergenler olmayanlara göre 17 kat daha yüksek oranda intihar girişimine eğilimlidir $(16,17,20)$. Major depresif bozukluk tanısılla izlenen ergenlerin yaklaşık \%70'inde intihar düşüncesinden ya da girişiminden bahsedilmiştir (20). Yine intihar girişiminde bulunan 119 ergende yapılan bir çalışmada (ort 17 yaş), \%91'inde en az bir psikiyatrik tanı olduğu ve psikiyatrik tanı varlığının genellikle 16 yaşından daha büyük olan grupta belirgin olduğu gösterilmiştir (20).

Çalışmamızda olguların altısında daha önceden tanı almış kronik hastalık öyküsü (psikiyatrik hastalık dışı: epilepsi, astım) saptanmıştır. Ergenler kronik hastalıklar gibi sağlık sorunlarına diğer gelişim süreçlerinde olan bireylerden farklı tepkiler verebilmektedirler. Bazı ergenler bu duruma boyun eğerken, bazıları durumu kabullenip ilaçları konusunda aşırı dikkatli ve titiz davranırken, bazıları da bağımsızlığını belirtme gereksinimiyle tehlikeli ve isyankar davranışlarda bulunabilirler (21). 
İntoksikasyon vakalarının bir kısmı birden fazla türde ilacı birlikte almış olabilir. Yapılan çalışmalarda çoklu ilaç kullanım oranı \%74 (17) ve \%52,5 (5) olarak verilmiştir. Bizim çalışmamızdaki çoklu ilaç kullanımına bağlı intoksikasyon oranı da (\%60) bu çalışmalara benzerdir. Bu durum ergenlerin intihar düşüncesinin ve yaşamı sonlandırma isteklerinin belirgin olabileceğini düşündürmektedir.

İntoksikasyon ile başvuran hastalarda en sık görülen semptomlar bulantı-kusma, baş ağrısı, baş dönmesi, dalgınlık, huzursuzluk, karın ağrısı, solunum sıkıntısı, ishal, ağız mukozasında hiperemi ve konvülziyondur $(12,18,19,22)$. Hastalarımızda da en sik bulant1-kusma ve karın ağrısı gözlenmiştir.

İntoksikasyonlarda mortalitenin \%0,4-5 olduğu ifade edilmektedir (22). Çalışmamızda, madde bağımlısı bir hastada yüksek doz LSD alımına bağlı solunum yetmezliği gelişmiş ve mekanik ventilasyon ihtiyacı olmuştur. Ayrıca kolşisin intoksikasyonu olan bir hastaya ise hemodiyafiltrasyon uygulanmıştır. Bu iki hasta yoğun bakım takipleri sonlandıktan sonra servise çıkarılarak taburcu edilmiştir. Çalışmamızda hiçbir hastada mortalite görülmemiştir. Benzer olarak Türkmenoğlu ve ark. (19) ile Dinleyici ve ark. (10) ergen ilaç intoksikasyonunda mortalite olmadığını belirtmişlerdir. Organofosfat ile intoksikasyonlara bağlı ölüm oranları daha yüksek olmasına rağmen, çalışmamızda kaza sonucu tarım ilacına maruz kalan hastalarda mortalite görülmemiştir $(18,23)$.

Birçok intoksikasyonda erken dönemde yapılan tıbbi müdahaleler ile henüz toksik etki oluşmadan vücut dışına atılması, absorbe edilmesi veya antidot kullanımıla zararlı etkilerinin ortaya çıkmaması sağlanabilir. Antidotlar, ciddi zehirlenmeler sonucu meydana gelen hastalık ve ölüm oranını azaltmaları nedeniyle hayati öneme sahiptir (12). Lokal bir antidot olan aktif kömür en sık kullanılan antidottur (12). Yoğun bakımımıza kabul edilen hastaların 42'sine (\%70) aktif kömür tedavisi verilmiştir. Bir demir intoksikasyonu hastasına desferoksamin, iki asetaminofen zehirlenmesine $\mathrm{N}$-asetilsistein ile spesifik antidot uygulaması yapılmıştır.

\section{SONUÇ}

Çalışmamız ergen intoksikasyonları üzerine yapılan çalışmalar ile uyumlu olmakla birlikte; çalışmamızda hastaların çoğunluğunu intihar amacıyla ilaç alan kız ergenlerin oluşturduğu ve eşlik eden psikiyatrik hastalık oranının yüksek olduğu dikkat çekmektedir. En çok ilaç alımının antidepresan ve analjezik grubundan olmasindan dolayı risk grubunda bulunan ergenlere önleyici amaçlı psikiyatrik değerlendirmenin önemli olduğunu düşünmekteyiz.
Çalışmamızın geriye dönük olması, bu nedenle verilerin değerlendirilmesinde sadece hasta dosya bilgilerinin kullanılması, intoksikasyon etkenlerinin hasta ve yakınının beyanı üzerine olması ve psikiyatrik tanıların açı olarak belirtilmemesi bu çalı̧manın en büyük kısıtlılığıdır. Ayrıca çalışmanın tek bir ilde ve merkezde yapılması sonuçların genelleştirilmesini engellemektedir.

\section{ETİK BEYANLAR}

Etik Kurul Onayı: Çalışma için Malatya Klinik Araştırmalar Etik Kurulu’ndan 2019 tarih, 2019/135 sayı/ karar no ile etik kurul onayı alınmıştır.

Aydınlatılmış Onam: Çalışma retrospektif olarak dizayn edildiği için hastalardan aydınlatılmış onam alınmamıştır.

Hakem Değerlendirme Süreci: Harici çift kör hakem değerlendirmesi.

Çıkar Çatışması Durumu: Yazarlar bu çalışmada herhangi bir çıkara dayalı ilişki olmadığını beyan etmişlerdir.

Finansal Destek: Yazarlar bu çalışmada finansal destek almadıklarını beyan etmişlerdir.

Yazar Katkıları: Yazarların tümü; makalenin tasarımına, yürütülmesine, analizine katıldıklarını ve son sürümünü onayladıklarını beyan etmişlerdir.

\section{KAYNAKLAR}

1. Karabel D, Bozkurt F, Sabaz MN, Şahin C, Sabaz MN, Haspolat YK. Yoğun bakıma yatış endikasyonlarının önemli bir nedeni: Çocuk ve adolesan akut zehirlenmeleri. Konuralp Tip Derg 2016; 8: $1-4$.

2. Akın E, Berkem M. İntihar girişiminde bulunan ergenlerde olumsuz yaşam olayları: vaka kontrol çalışması. Fırat Tıp Derg 2013; 18: 26-9.

3. Dogan H, Adıgüzel L, Uysal E, Sarıkaya S, Özüçelik DN, Okuturlar Y. Differences between adolescent and adult cases of suicidal drug intoxication. Bakirkoy Tip Derg 2016; 12: 20-3.

4. Bayraktar S. İntihar kavramının çocuklar ve ergenler açısından ele alınması. Akdeniz İnsani Bilimler Derg 2015; 5: 139-59.

5. Ünlü G, Aksoy Z. İntihar girişiminde bulunan çocuk ve ergenlerin değerlendirilmesi. Pamukkale Tip Derg 2011; 7: 176-83.

6. Aktepe E, Kandil S, Göker Z, Sarp K, Topbaş M, Özkorumak E. İntihar girişiminde bulunan çocuk ve ergenlerde sosyodemografik ve psikiyatrik özelliklerin değerlendirilmesi. TSK Koruyucu Hekimlik Bült 2006; 5: 444-54.

7. Atay IM, Kerimoğlu E. Ergenlerde intihar davranışı. Çocuk Gençlik Ruh Sag Derg 2003; 10: 128-36.

8. Soylu N, Taneli Y, Taneli S. Depresyonu olan ergenlerde intihar davranışını etkileyen sosyal, emosyonel ve kognitif faktörlerin araştırılması. Nöropsikiyatri Arşivi 2013; 50: 352-9.

9. Freeman JB, Garcia AM, Leonard HL. Anxiety disorders child and adolescent psychiatry. Lewis's Child and Adolescent Psychiatry: Philadelphia,2002: 821-34. 
10.Dinleyici M, Kıral E, Yazar AS, Sahin S. İlaç intoksikasyonu ile başvuran ergenlerde özkıyım ilişkili risk faktörlerin değerlendirilmesi. Osmangazi Tip Derg 2018; 41: 166-72.

11. Tekerek NÜ, Dursun A, Akyıldız BN. Retrospective analysis of poisoning cases our followed in pediatric intensive care unit. Çocuk Acil Yoğun Bakım Derg 2016; 3: 21-6.

12.Özsoylu S, Kondolot M, Akyıldız B, Özmen S, Demirci E. Evaluation of children and adolescents admitted to intensive care due to suicide attempts. Bakirkoy Tip Derg 2019; 15: 131-5.

13.Özcan N, İkincioğulları D. Ulusal ZehiR Danışma Merkezi 2008 Yılı Çalişma Raporu Özeti. Türk Hijyen ve Deneysel Biyol Derg 2009; 66: 29-58.

14.Özdemir R, Bayrakci B, Tekşam Ö, Kale G. Thirty-three-year experience on childhood poisoning. Turk J Pediatr 2012; 54: 251-9.

15. Kaplan HI, Sadock BJ. Kaplan sadock's comprehensive textbook of psychiatry. 2nd ed: 2007.

16. Suominen KH, Isometsä ET, Henriksson M. Inadequate treatment for major depression both before and after attempted suicide. Am. J Psychiatr 1998; 155: 1778-80.

17. Yalaki Z, Taşar MA, Yalçın N, Bilge YD. Cocukluk ve gençlik dönemindeki özkıyım girişimlerinin değerlendirilmesi. Ege Tip Derg 2011; 50: 125-8.

18. Dağlı R, Kocaoğlu N, Bayır H, Hakkı M, Erbesler ZA, Kahraman M. Yoğun bakım servisimizdeki intoksikasyon vakalarının incelenmesi. Muğla Sitkı Koçman Üniv Tip Derg 2016; 3: 17-20.

19. Türkmenoğlu Y, Akşahin BG, Sarıtaş Ü, Yılmaz B, Arat C, Şafak E. Update glance on childhood intoxication. Okmeydanı Tip Derg 2015; 31: 82-91.

20. Myers K, Mccauley E, Calderon R, Mitchell J, Burke P, Schloredt K. Risks for suicidality in major depressive disorder. J Am Acad Child Adolesc Psychiatr 1991; 30: 86-94.

21.Gökler B. Ölümcül hastalık karșısında çocuk, aile ve hekim. Ben hasta değilim. Çocuk Sağlığı ve Hastalıklarının Psikososyal Yönü, 1999: 471-5.

22. Andiran N, Sarikayalar F. Pattern of acute poisoning in childhood in Ankara: What has change in twenty years?. Turk J Pediatr 2004; 46: $147-52$.

23. Ahmet Aydın. Yoğun bakım ünitesinde takip edilen zehirlenme olgularının değerlendirilmesi: retrospektif çalışma. Fırat Med J 2019; 3: 129-33. 